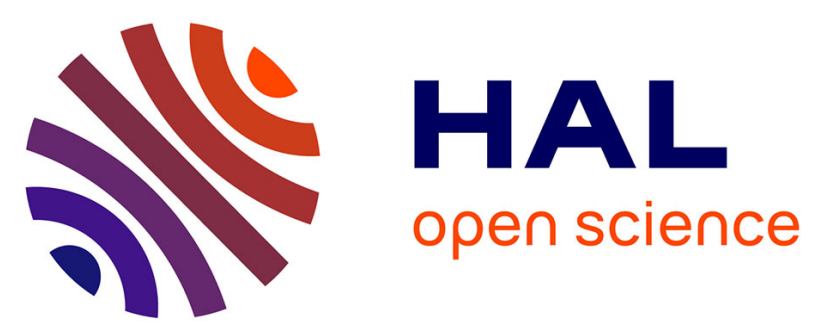

\title{
Cognitive procedural learning in early Alzheimer's disease: impaired processes and compensatory mechanisms.
}

Hélène Beaunieux, Francis Eustache, Philippe Busson, Vincent de La Sayette, Fausto Viader, Béatrice Desgranges

\section{To cite this version:}

Hélène Beaunieux, Francis Eustache, Philippe Busson, Vincent de La Sayette, Fausto Viader, et al.. Cognitive procedural learning in early Alzheimer's disease: impaired processes and compensatory mechanisms.: Cognitive procedural learning in Alzheimer's disease. J Neuropsychol, 2012,6 (1), pp.31-42. 10.1111/j.1748-6653.2011.02002.x . inserm-00649632

\section{HAL Id: inserm-00649632 https://www.hal.inserm.fr/inserm-00649632}

Submitted on 30 Mar 2012

HAL is a multi-disciplinary open access archive for the deposit and dissemination of scientific research documents, whether they are published or not. The documents may come from teaching and research institutions in France or abroad, or from public or private research centers.
L'archive ouverte pluridisciplinaire HAL, est destinée au dépôt et à la diffusion de documents scientifiques de niveau recherche, publiés ou non, émanant des établissements d'enseignement et de recherche français ou étrangers, des laboratoires publics ou privés. 
Cognitive procedural learning in early Alzheimer's disease: impaired processes and compensatory mechanisms

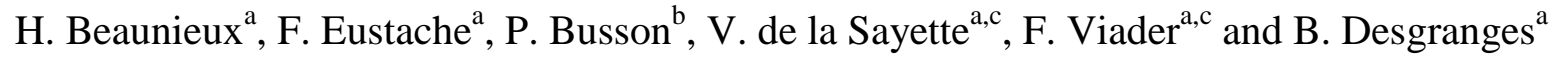

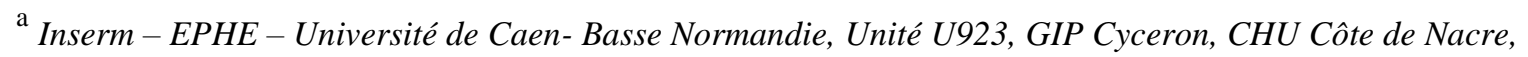
Caen, France

${ }^{\mathrm{b}}$ CH Avranches-Granville, Service de neurologie, Avranches, France

${ }^{\mathrm{c}} \mathrm{CHU}$ Caen, Service de neurologie, Caen, France

Short title: Cognitive procedural learning in Alzheimer's disease.

Corresponding author: Hélène Beaunieux, Unité Inserm-EPHE-Université de Caen-Basse Normandie U923, UFR de Psychologie, Université de Caen-Basse Normandie, esplanade de la Paix, 14032 Caen Cedex, France

Tel.: +33-2-31-065196 Fax: +33-2-31-065198

E-mail address: helene.beaunieux@unicaen.fr 


\begin{abstract}
Introduction: The aim of this study was to study cognitive procedural learning in early Alzheimer's disease (AD). Methods: Cognitive procedural learning was assessed using the Tower of Hanoi task. In order to take account of possible interactions between different systems during cognitive procedural learning, we also measured nonverbal intellectual functions, working memory and declarative memory. Results: Our results showed an apparent preservation of cognitive procedural learning in $\mathrm{AD}$ and a deleterious effect of the disease on verbal intelligence and declarative memory. Correlational analyses revealed a difference between $\mathrm{AD}$ patients and control participants in the type of processing they applied to the task. Conclusion: The noninvolvement of declarative memory would appear to be partly responsible for a slowdown in the cognitive procedural dynamics of $\mathrm{AD}$ patients. As the $\mathrm{AD}$ patients were unable to use their declarative memory, they were still in a problem-solving mode at the end of the learning protocol and had to implement higher-order cognitive processes (i.e., compensatory mechanisms) to perform the procedural task.
\end{abstract}

Keywords: procedural memory, declarative memory, working memory, Tower of Hanoi task, learning, compensatory mechanisms. 


\section{Introduction}

In cognitive rehabilitation, it is vital to assess procedural learning in order to gauge patients' ability to learn new procedures. Given that, unlike declarative and working memory, perceptual-motor and perceptual-verbal procedural learning abilities may be preserved in Alzheimer's disease (AD) (see van Halteren-van Tilborg et al., 2007, for review), occupational rehabilitation based on cognitive procedural learning may be useful for some patients with AD (Bourgeois et al., 2003; Camp et al., 2004; Lekeu et al., 2002; Oriani et al., 2003; Thivierge et al., 2008). Little, however, is known about cognitive procedural learning in $\mathrm{AD}$. Most studies of procedural learning in $\mathrm{AD}$ have focused on the learning of perceptual-motor procedures (such as the rotor test) and found preserved learning ability and performance levels for this kind of task (Bondi \& Kaszniak, 1991; Bondi et al., 1993; Deweer et al., 1994; Dick et al., 1995, 1996, 2000, 2003; Eslinger \& Damasio, 1986; Heindel et al., 1988; Heindel et al., 1989; see van Halteren-van Tilborg et al., 2007, for a review). Research on the ability to learn perceptual-verbal procedures in $\mathrm{AD}$ has mainly been based on data collected using a mirror-reading task. Although researchers adopting this procedure have obtained discrepant results, these can be explained to some extent by methodological differences and/or differences in disease severity (Desgranges et al., 1996; Deweer et al., 1993; Deweer et al., 1994; Grober et al., 1992; Merbah et al., 2010). A handful of studies have investigated cognitive procedural learning in AD using jigsaw puzzles (Grafman et al., 1990; Hirono et al., 1996; Poe \& Seifert, 1997), but they have yielded conflicting results. While Grafman et al. reported impairment of the patients' ability to improve their performances or even complete the task, Hirono et al. (1996) and Poe and Seifert (1997) suggested that cognitive procedural learning is preserved. As before, these divergent findings can be explained partly by differences in the jigsaw-learning tasks, which varied in complexity and number of trials, and partly by differences in the severity of the 
dementia.

Above and beyond these discrepancies, which make it difficult to compare findings, none of the above-mentioned studies of procedural learning in AD considered the nonprocedural cognitive functions involved in the encoding and retrieval of information in procedural memory. And yet, research carried out in the fields of neuropsychology (Baddeley \& Wilson, 1994; Pitel et al., 2007; Schmidtke et al., 1996, 2002; Winter et al., 2001; Xu \& Corkin, 2001), neuroimaging (Hubert et al., 2007, 2009) and experimental psychology (Ackerman, 1988; Anderson, 1987; Beaunieux et al., 2006, 2009; Wotz, 1988) has shown that cognitive procedural learning relies on nonprocedural functions (Eustache \& Desgranges, 2008) that can be considered through the cognitive determinants of cognitive procedural levels (i.e., the cognitive functions required to perform the procedural task at a certain point in the learning process; Ackerman, 1988; Beaunieux et al., 2006, 2009; Pitel et al., 2007; Schmidtke et al., 1996, 2002; Woltz, 1988).

The contribution of cognitive functions to procedural performances has been theorized in the ACT model (Adaptive Control of Thoughts; Anderson, 1987). According to this model, cognitive procedural learning occurs in three qualitatively different phases (cognitive, associative and autonomous) and involves different types of processing. Performing a new cognitive procedural task requires processes which are highly controlled in the initial, cognitive phase, and more automatic ones in the last, autonomous, phase. The associative phase is regarded as a transitional phase between the first and last ones. Ackerman (1988) showed that during the cognitive phase, performance levels are associated with general intelligence, while in the autonomous phase individual differences in performance are mainly determined by psychomotor functions. Alongside these two functions (intelligence and psychomotor functions), Woltz (1988) has demonstrated that working memory is also a major cognitive determinant of individual differences in the first phase. Drawing on Anderson's (1987) 
and Ackerman's (1988) theoretical conceptions, we confirmed the existence of three qualitatively different learning phases (cognitive, associative and autonomous) in healthy young participants using the Tower of Toronto (TT) task (Beaunieux et al., 2006). We also identified specific cognitive determinants of procedural performance levels for both the cognitive phase (intellectual abilities, working and declarative memory) and the autonomous phase (psychomotor abilities). In a more recent study, we found that older participants, unlike their younger counterparts, did not spontaneously invoke declarative memory and displayed a slowdown in cognitive procedural learning, as well as delayed involvement of working memory in this learning process (Beaunieux et al., 2009). These results are in accordance with Baddeley and Wilson (1994), Winter et al. (2001), and Xu and Corkin (2001), who have all underlined the major contribution of declarative memory to procedural learning. These authors suggest that declarative memory of previous learning episodes can be called upon to eliminate errors on subsequent trials. Thus, declarative memory plays a role in improving procedural performance throughout the learning process. Given the well-established effect of AD on declarative memory, we can reasonably assume the dynamics of cognitive procedural learning to be disturbed in these patients and the appearance of preserved cognitive procedural learning in AD (Dick et al., 1995, 1996, 2000, 2003; Hirono et al., 1996) to be just that-mere appearance. We would expect patients with early AD to be forced by their declarative memory deficits to implement different learning strategies (i.e., compensatory mechanisms) from those implemented by controls.

The aim of this study was to investigate cognitive procedural learning in a group of patients suffering from early $\mathrm{AD}$ and a group of older control participants by means of a cognitive procedural test, the Tower of Hanoi (TH). We focused our study on the first two phases of cognitive procedural learning (cognitive and associative phases) because they involve working memory, declarative memory and intelligence. 


\section{Method}

\subsection{Participants and selection procedure}

Eighteen AD patients with mild to moderate dementia and 18 controls were examined.

The patients, all right-handed, suffered from probable AD according to the criteria established by McKhann et Al. (1984). All the patients underwent a neurological examination, standard blood tests, an electroencephalogram (EEG), and a standard neuropsychological assessment to ensure that none of them had an oral comprehension impairment. CT scans and MRI revealed no anomaly other than diffuse cerebral atrophy. The patients had no previous neurological or psychiatric history. The control participants were matched with the patients on age and education level (cf. Table 1).

\section{Insert Table 1}

All participants gave their consent to the study after detailed information was provided both to them and to their caregivers, and the study was conducted in line with the Declaration of Helsinki. All the patients were competent to give informed consent and did so.

\subsection{General procedure}

Our protocol comprised a cognitive procedural learning task $(\mathrm{TH})$ and a set of complementary cognitive tests. The whole of the experimental protocol represented three hours of examinations for healthy controls and five hours for patients, spread over two days.

\subsubsection{Cognitive procedural task: Tower of Hanoi (TH) task.}

The Tower of Hanoi is more straightforward than its isomorphic variant the Tower of Toronto (Beaunieux et al., 2006, 2009). The material of the TH task was composed of a wooden block with 3 vertical pegs of equal height. Four wooden disks of decreasing diameter were stacked on the left-hand peg. The task consisted in rebuilding the pyramid of 4 disks on the right-hand peg while obeying two rules: never place a larger disk on top of a smaller one and only move one disk at a time. The rules were read out to participants and explained 
through examples of authorized and unauthorized moves. Before each procedural learning session, we made sure that the oral instructions were fully understood. Participants were corrected online whenever they violated a rule. Each time they completed a trial, they were congratulated on their good performance. The minimum number of moves to solve the 4-disk TH task is 15 .

Learning the cognitive procedure took place over three sessions: Sessions 1 and 2 were separated by a retention period of two hours, while Sessions 2 and 3 took place 20 hours apart, including a period of sleep. Each learning session comprised five consecutive trials, meaning that participants could carry out the TH task a total of 15 times. The participants'

performances on the TH task were assessed in terms of time and the number of moves needed to complete it.

\subsubsection{Complementary tests}

2.2.2.1. Intellectual abilities were measured by the Verbal IQ score of the Wechsler Adult Intelligence Scale (WAIS-R; Wechsler, 1989; Cargnello \& Gurekas, 1988).

2.2.2.2. Working memory was tested by means of two tasks. The phonological loop was assessed on a task involving the serial repetition of a series of digits (digit span) taken from the WAIS-R. The visuospatial sketchpad was assessed on the reproduction of spatial sequences (visuospatial span), in a task taken from Signoret's BEM-144 (Signoret, 1991).

2.2.2. Declarative memory was assessed using the California Verbal Learning Test (CVLT; Delis et al., 1991; Deweer et al., 1994). Six scores were obtained: a learning score, two immediate recall scores (free and cued recall), two delayed recall scores (free and cued recall) and a recognition score.

\subsection{Statistical analysis}

Statistical analyses were conducted in three steps.

\subsubsection{Assessment of cognitive procedural learning}


Performances on the TT task were assessed by means of two variables: the number of moves and the time (in seconds) taken to complete each trial. We aggregated the data for each five-trial session, which yielded a more stable estimate of performance for each group and limited the number of correlations that subsequently had to be calculated. A multivariate analysis of variance (MANOVA) was carried out, with performance on the three sessions as the repeated measure and group as a between-participants factor. Complementary analyses on each session were conducted by mean of $t$-tests.

\subsubsection{Effect of AD on complementary cognitive tasks}

Unpaired Student's $t$-tests were carried out in order to compare the two groups' scores on the complementary cognitive tasks. For verbal intelligence and working memory, raw scores were used, while for declarative memory all the declarative raw scores were converted into standard units ( $z$-scores) and averaged into a single composite score.

\subsubsection{Cognitive procedural learning dynamics}

In order to study the cognitive procedural learning dynamics, Pearson correlation coefficients were computed within each group to examine the relationship between procedural learning levels (total time per session) and cognitive determinants of levels of performance for the cognitive phase (verbal intellectual abilities, declarative memory and working memory; see Introduction). Finally, within the context of the correlation results, multiple regressions were performed to assess the contribution of selected variables to procedural learning scores, in order to identify the best predictor for each learning session in each group. We compared the $\beta$ coefficients of the two groups to estimate whether patients invoked the same learning strategies as controls.

We chose not to consider the number of moves for the correlations and regressions, as it was not sufficiently sensitive. This variable loses its variability as soon as the participants 
have found the solution to the problem and thus does not reflect the automation of the cognitive procedure.

A probability level of 0.05 was adopted for all the analyses. Bonferroni corrections for multiple comparisons were applied.

\section{Results}

\subsection{Assessment of cognitive procedural learning}

Regarding the time taken to solve the TH task, the MANOVA showed a significant group effect, $F(1,34)=207.7 ; p<.0001$ and a significant session repetition effect, $F(2,68)=$ 41.24; $p<.0001$, but no significant interaction between the two, $F(2,68)=2.5 ; p<.09$ (Fig. 1A). $T$-tests conducted for each session showed that there was a significant difference between the two groups on all three sessions (Session 1: $t(34)=4.38, p<.0001$; Session 2: $t(34)=3.5, p<.001$ and Session 3: $t(34)=3.6, p<.0001)$.

\section{Insert Figure 1}

In terms of the number of moves, the MANOVA revealed no effect of group, $F(1,34)$ $=0.51 ; p=0.47$, a significant session repetition effect, $F(2,68)=6.67 ; p=0.002$, and no interaction between the two, $F(2,68)=1.37 ; p=0.26$ (Fig. 1B). $T$-tests conducted for each session showed no significant difference between the two groups on the first two sessions $($ Session 1: $t(34)=0.35, p=.72 ;$ Session 2: $t(34)=0.01, p=.99)$, but a difference approaching significance for the last session (Session 3: $t(34)=1.7, p=0.09$ ).

\subsection{Effect of AD on complementary cognitive tasks}

Unpaired Student's $t$-tests carried out on performances on the complementary cognitive tasks showed an overall impairment in the AD group. Patients' scores were significantly lower for the tests measuring verbal intelligence and declarative memory (Table 
2). Differences in working memory scores did not reach significance.

Insert Table 2

\subsection{Cognitive procedural learning dynamics}

The dynamics of cognitive procedural learning was examined by analyzing the correlations in each group and for each session between the time taken to solve the TH task and verbal intelligence, working memory and declarative memory scores, each taken separately. Table 3 shows the correlations observed in each group. The pattern of significant correlations differed according to the group. In the control group, significant correlations were only found for the first session, where procedural performance levels were significantly correlated with verbal intelligence and declarative memory. Regression analyses showed that the sole predictor of procedural learning performance was declarative memory, accounting for $38 \%$ of the variance in Session 1 (Table 4). In the AD group, correlations with verbal intelligence and the phonological loop were significant for the first session (Table 3). For the two last sessions, only correlations with verbal intelligence were significant. Declarative memory was never significantly linked with procedural performance levels. Regression analyses showed that the best predictors of procedural results were the phonological loop in Session 1 and verbal intelligence in Sessions 2 and 3 (accounting for 32\%, 29\% and 28\% of the variance, respectively). The slopes corresponding to the controls' predictor for Session 1 and the patients' predictor for Session 4 differed significantly (Table 4).

\section{Discussion}

Our results showed relative preservation of cognitive procedural learning in $\mathrm{AD}$, as assessed by the TH task. Although the time taken to solve the TH task and the number of moves required suggested that the patients were slower, they seemed to learn the procedure in almost the same way as the controls, as attested to by the lack of a significant interaction between 
group and session for the two variables. Correlational analyses revealed a difference in the dynamics of cognitive procedural learning between $\mathrm{AD}$ patients and controls.

Results revealed an expected deterioration in intelligence and declarative memory (Greenaway et al., 2006; Hamilton et al., 2004; Lamar et al., 2004) in the AD patients, associated with preserved short-term memory. Comparisons of working memory scores failed to reveal any significant difference. As suggested in a recent review (Huntley \& Howard, 2010), these results may reflect continuing normal function of the slave systems of working memory, which only deteriorate as the disease progresses.

The deleterious effect of $\mathrm{AD}$ on verbal intelligence and declarative memory seems to have an impact on cognitive procedural learning dynamics. The differences between the two groups in terms of the correlations between verbal intelligence, working memory and declarative memory on the one hand, and cognitive procedural levels on the other hand, can help us to understand the effect of AD on cognitive procedural learning dynamics. In the controls, the link between procedural performance levels and intelligence and declarative memory scores in the first session confirmed the results of our previous studies and suggested that the controls were in the cognitive phase of procedural learning at that point. The absence of any correlation in the final learning session suggests that by then, they had graduated to the associative phase, which no longer requires the massive intervention of nonprocedural cognitive functions (Beaunieux et al., 2006, 2009).

The pattern of correlations observed in AD patients was radically different. Unlike the controls, the AD patients did not seem to draw on their declarative memory at all during the first procedural learning session. Working memory and verbal intelligence alone seemed to contribute to procedural performance levels throughout the learning process.

Thus, despite the absence of major differences in procedural performances, these data reveal a clear difference in the type of processing applied by each group to perform the 
procedural task. AD patients seemed to draw massively on their verbal intelligence throughout the learning process and to remain in the cognitive phase right to the very the end of the task. This result indicates that, as expected, AD patients used a compensatory mechanism to attempt to attain the same learning level as the control participants. These data are in accordance with those reported by Schmidtke et al. (1996) for amnesic patients and by Pitel et al. (2007) for alcoholic patients. They suggest that AD patients were still in a problem-solving mode at the end of the learning protocol, and that they implemented higherorder cognitive processes. Like Schmidtke et al. (1996) and Pitel et al. (2007), we consider that the AD patients' prolonged dependence on intelligence suggests that their transition from the initial, cognitive phase to later phases of cognitive skill acquisition was delayed. This hypothesis was strengthened by the analysis of the contribution of declarative memory to procedural performance levels. Our examination of correlation patterns within the two groups showed that controls made extensive use of declarative memory in the first learning session. AD patients, on the other hand, displayed massive impairment of declarative memory, which hampered the procedural learning process by preventing the effective correction of errors. Because they were unable to use their declarative memory to make progress, AD patients had greater difficulty generating the cognitive procedure that had to be automated.

Finally, our results emphasize the relevance of errorless learning in promoting cognitive procedural learning in AD. Errorless learning "refers to a learning condition that involves the elimination of errors during the learning process" (Clare \& Jones, 2008). Thus, the main goal of this learning technique is to compensate for the deficits of declarative memory, which is assumed to be in charge of error elimination (Baddeley \& Wilson, 1994). Most of the studies that have investigated the effect of errorless learning in AD have reported a beneficial effect on semantic learning (Dunn \& Clare, 2007; Haslam et al., 2006; Ruis \& Kessels, 2005). To date, Kessels and Hensken (2009) are the only authors to have investigated 
the effect of errorless learning on procedural learning in AD in a controlled group design. They reported a beneficial effect of errorless learning on new skill acquisition. In line with this study, our data suggest that massed learning conditions associated with an errorless learning method could be beneficial to patients in the first cognitive procedural learning phase. This learning method could allow them to reach the autonomous phase more quickly and thus benefit from the positive effects of sleep in the consolidation of information in procedural memory over the following nights (Hauptmann et al., 2005; Rauchs et al., 2004; Walker, 2005). Thus, we could imagine a learning method associating the positive effects of an initial massed errorless learning condition with those of a subsequent distributed learning one. Further research is now needed to put this proposal to the test from an experimental point of view. 


\section{REFERENCES}

Ackerman, P. L. (1988). Determinants of individual differences during skill acquisition: cognitive abilities and information processing. Journal of Experimental Psychology: General, 117, 288-318.

Anderson, J. R. (1987). Skill acquisition: Compilation of weak-method problem solutions. Psychological Review, 94, 192-210.

Baddeley, A., \& Wilson, B. A. (1994). When implicit learning fails: amnesia and the problem of error elimination. Neuropsychologia, 32, 53-68.

Beaunieux, H., Hubert, V., Desgranges, B., \& Eustache, F. (2009). Episodic memory deficits slow down the dynamics of cognitive procedural learning in normal aging. Memory 17, 197-207.Belleville, S., Peretz, I., \& Malenfant, D. (1996). Examination of the working memory components in normal aging and in dementia of the Alzheimer type. Neuropsychologia, 34, 195-207.

Beaunieux, H., Hubert, V., Witkowski, T., Pitel, A. L., Rossi, S., Danion, J. M., Desgranges, B., \& Eustache, F. (2006). Which processes are involved in cognitive procedural learning? Memory. 14, 521-539.

Bondi, M. W., \& Kaszniak, A. W. (1991). Implicit and explicit memory in Alzheimer's disease and Parkinson's disease. Journal of Clinical and Experimental Neuropsychology, 13, 339-358.

Bondi, M. W., Kaszniak, A. W., Rapcsak, S. Z., \& Butters, M. A. (1993). Implicit and explicit memory following anterior communicating artery aneurysm rupture. Brain and Cognition, 22, 213-229.

Bourgeois MS, Camp C, Rose M, White B, Malone M, Carr J, Rovine M. (2003). A comparison of training strategies to enhance use of external aids by persons with dementia. Journal of Communication Disorders,36, 361-78.

Camp, C., \& Skrajner, M. (2004). Resident-assisted Montessori programming (RAMP): Training persons with dementia to serve as group activity leaders. Gerontologist, 44, 42631.

Cargnello, J. C., \& Gurekas, R. (1988). The WAIS-SAM: a comprehensive administrative model of modified WAIS procedures. Journal of Clinical Psychology, 44, 266-270. 
Clare L, Jones RS. (2008). Errorless learning in the rehabilitation of memory impairment: a critical review. Neuropsychology Review, 18, 1-23.

Delis, D. C., Massman, P. J., Butters, N., Salmon, D. P., Cermak, L. S., \& Kramer, J. H. (1991). Profiles of demented and amnesic patients on the California Verbal Learning Test: Implications for the assessment of memory disorders. Psychological Assessment: A Journal of Consulting and Clinical Psychology, 3, 19-26.

Desgranges, B., Eustache, F., Rioux, P., de la Sayette, V., \& Lechevalier, B. (1996). Memory disorders in Alzheimer's disease and the organization of human memory. Cortex, 32, 387412.

Deweer, B., Ergis, A. M., Fossati, P., Pillon, B., Boller, F., Agid, Y., \& Dubois, B. (1994). Explicit memory, procedural learning and lexical priming in Alzheimer's disease. Cortex, 30, 113-126.

Deweer, B., Pillon, B., Michon, A., \& Dubois, B. (1993). Mirror reading in Alzheimer's disease: normal skill learning and acquisition of item-specific information. Journal of Clinical and Experimental Neuropsychology, 15, 789-804.

Dick, M. B., Hsieh, S., Bricker, J., \& Dick-Muehlke, C. (2003). Facilitating acquisition and transfer of a continuous motor task in healthy older adults and patients with Alzheimer's disease. Neuropsychology, 17, 202-12.

Dick, M. B., Hsieh, S., Dick-Muehlke, C., Davis, D. S., \& Cotman, C. W. (2000). The variability of practice hypothesis in motor learning: does it apply to Alzheimer's disease? Brain and Cognition, 44, 470-89.

Dick, M. B., Shankle, R. W., Beth, R. E., Dick-Muehlke, C., Cotmant, C. W., \& Kean, M. L. (1996). Acquisition and long-term retention of a gross motor skill in Alzheimer's disease patients under constant and varied practice conditions. Journal of Gerontology, 51, 103111.

Dick, M. B., Nielson, K. A., Beth, R. E., Shankle, W. R., \& Cotman, C. W. (1995). Acquisition and long-term retention of a fine motor skill in Alzheimer's disease. Brain and Cognition, 29, 294-306.

Dunn J, Clare L. (2007). Learning face-name associations in early-stage dementia: comparing the effects of errorless learning and effortful processing. Neuropsychological Rehabilitation, 17, 735-54. 
Eslinger, P. J., \& Damasio, A. R. (1986). Preserved motor learning in Alzheimer's disease: implications for anatomy and behavior. Journal of Neuroscience, 6, 3006-3009.

Eustache, F. \& Desgranges, B. (2008). MNESIS: towards the integration of current multisystem models of memory. Neuropsychology Review, 18, 53-69.

Grafman, J., Weingartner, H., Newhouse, P. A., Thompson, K., Lalonde, F., Litvan, I., Molchan, S., \& Sunderland, T. (1990). Implicit learning in patients with Alzheimer's disease. Pharmacopsychiatry, 23, 94-101.

Greenaway MC, Lacritz LH, Binegar D, Weiner MF, Lipton A, Munro Cullum C. (2006). Patterns of verbal memory performance in mild cognitive impairment, Alzheimer disease, and normal aging. Cognitive and Behavioral Neurology, 19, 79-84.

Grober, E., Ausubel, R., Sliwinski, M., \& Gordon, B. (1992). Skill learning and repetition priming in Alzheimer's disease. Neuropsychologia, 30, 849-858.

van Halteren-van Tilborg IA., Scherder EJ, Hulstijn W. (2007). Motor-skill learning in Alzheimer's disease: a review with an eye to the clinical practice. Neuropsychology Review, 17, 203-12.

Hamilton, J. M., Salmon, D. P., Galasko, D., Delis, D. C., Hansen, L. A., Masliah, E., Thomas, R. G., \& Thal, L. J. (2004). A comparison of episodic memory deficits in neuropathologically-confirmed dementia with Lewy bodies and Alzheimer's disease. Journal of the International Neuropsychological Society, 10, 689-697.

Haslam C, Gilroy D, Black S, Beesley T. (2006). How successful is errorless learning in supporting memory for high and low-level knowledge in dementia. Neuropsychological Rehabilitation, 16, 505-36.

Hauptmann, B., Reinhart, E., Brandt, S. A., \& Karni, A. (2005). The predictive value of the leveling off of within-session performance for procedural memory consolidation. Brain Research Cognitive Brain Research, 24, 181-189.

Heindel, W. C., Butters, N., \& Salmon, D. P. (1988). Impaired learning of a motor skill in patients with Huntington's disease. Behavioral Neurosciences, 102, 141-147.

Heindel, W. C., Salmon, D. P., Shults, C. W., Walicke, P. A., \& Butters, N. (1989). Neuropsychological evidence for multiple implicit memory systems: a comparison of Alzheimer's, Huntington's, and Parkinson's disease patients. Journal of Neuroscience, 9, 582-587. 
Hirono, N., Mori, E., Ikejiri, Y., Imamura, T., Shimomura, T., Ikeda, M., Yamashita, H., Takatsuki, T., Tokimasa, A., \& Yamadori, A. (1996). Procedural memory in patients with mild Alzheimer's disease. Dementia and Geriatric Cognitive Disorders, 8, 210-216.

Hubert, V., Beaunieux, H., Chételat, G., Platel, H., Landeau, B., Danion, JM., Viader, F., Desgranges, B. \& Eustache, F. (2007). The dynamic network subserving the three phases of cognitive procedural learning. Human Brain Mapping. 28, 1415-29.

Hubert, V., Beaunieux, H., Chételat, G., Platel, H., Landeau, B., Danion, JM., Viader, F., Desgranges, B. \& Eustache, F. (2009). Age-related changes in the cerebral substrates of cognitive procedural learning. Human Brain Mapping, 30, 1374-86.

Huntley JD, Howard RJ. (2010). Working memory in early Alzheimer's disease: a neuropsychological review. International Journal of Geriatric Psychiatry, 25, 121-32.

Kessels RP, Hensken LM.(2009). Effects of errorless skill learning in people with mild-tomoderate or severe dementia: a randomized controlled pilot study. NeuroRehabilitation, $25,307-12$.

Lamar, M., Swenson, R., Kaplan, E., \& Libon, D. J. (2004). Characterizing alterations in executive functioning across distinct subtypes of cortical and subcortical dementia. Clinical Neuropsychology, 18, 22-31.

Lekeu, F., Wojtasik, V., Van der Linden, M., \& Salmon, E. (2002). Training early Alzheimer patients to use a mobile phone. Acta Neurologica Belgica, 102, 114-21.

McKhann, G., Drachman, D., Folstein, M., Katzman, R., Price, D., \& Stadlan, E. M. (1984). Clinical diagnosis of Alzheimer's disease: report of the NINCDS-ADRDA Work Group under the auspices of the Department of Health and Human Services Task Force on Alzheimer's Disease. Neurology, 34, 939-944.

Merbah S, Salmon E, Meulemans T. (2009). Impaired acquisition of a mirror-reading skill in Alzheimer's disease. Cortex. 22, in press.

Oriani M, Moniz-Cook E, Binetti G, Zanieri G, Frisoni GB, Geroldi C, De Vreese LP, Zanetti O. (2003). An electronic memory aid to support prospective memory in patients in the early stages of Alzheimer's disease: a pilot study. Aging and Mental Health, 7, 22-7.

Pitel, A.L., Witkowski, T., Vabret, F., Guillery-Girard, B., Desgranges, B., Eustache, F. \& Beaunieux, H. (2007). Effect of episodic and working memory impairments on semantic and cognitive procedural learning at alcohol treatment entry. Alcoholism: Clinical and 
Experimental Research, 31, 238-248.

Poe MK, Seifert LS. Implicit and explicit tests: evidence for dissociable motor skills in probable Alzheimer's dementia. (1997). Perceptual and Motor Skills, 85, 631-4.

Rauchs, G., Desgranges, B., Foret, J., \& Eustache, F. (2005). The relationships between memory systems and sleep stages. Journal of Sleep Research, 14, 123-40.

Ruis C, Kessels RP (2005). Effects of errorless and errorful face-name associative learning in moderate to severe dementia. Aging Clinical and Experimental Research, 17, 514-7.

Schmidtke, K., Handschu, R., \& Vollmer, H. (1996). Cognitive procedural learning in amnesia. Brain and Cognition, 32, 441-467.

Schmidtke, K., Manner, H., Kaufmann, R., \& Schmolck, H. (2002). Cognitive procedural learning in patients with fronto-striatal lesions. Learning and Memory, 9, 419-429.

Thivierge S, Simard M, Jean L, Grandmaison E. (2008). Errorless learning and spaced retrieval techniques to relearn instrumental activities of daily living in mild Alzheimer's disease: A case report study. Neuropsychiatric Disease and Treatment, 4, 987-99.

Signoret, J. L. (1991). Batterie d'efficience mnésique. Paris: Fondation IPSEN.

Walker, M. P. (2005) A refined model of sleep and the time course of memory formation. Behavioral and Brain Sciences, 28, 51-104.

Wechsler, D. A. (1989). Echelle d'intelligence pour adultes. Paris: ECPA.

Winter, W. E., Broman, M., Rose, A. L., \& Reber, A. S. (2001). The assessment of cognitive procedural learning in amnesia: Why the Tower of Hanoi has fallen down. Brain and Cognition, 45, 79-96.

Woltz, D. J. (1988). An investigation of the role of working memory in procedural skill acquisition. Journal of Experimental Psychology: General, 117, 319-331.

Xu, Y., \& Corkin, S. (2001). H.M. revisits the Tower of Hanoi puzzle. Neuropsychology, 15, $69-79$. 
Table 1: Characteristics of control participants and $\mathrm{AD}$ patients

Controls Patients

Number 18 18

Women/men $10 / 8$

$9 / 9$

Age (years)

$73.7 \pm 3.1$

$73.1 \pm 5.6$

Education level (years) ${ }^{\mathrm{a}}$ : mean $\pm S D$

$9.6 \pm 2.4$

$9.4 \pm 2.4$

$\operatorname{MDRS}^{\mathrm{b}}:$ mean $\pm S D$

$136.7 \pm 5.2$

$118.8 \pm 7.2 * * *$

Educational level is expressed in terms of years of schooling 
Table 2: Performances on the complementary tests

\begin{tabular}{|c|c|c|c|c|}
\hline \multirow{4}{*}{ Cognitive function } & \multirow{4}{*}{ Task } & Controls & \multicolumn{2}{|l|}{ AD } \\
\hline & & $n=18$ & \multicolumn{2}{|l|}{ Patients } \\
\hline & & mean $(S D)$ & $n=18$ & $p$ \\
\hline & & & mean $(S D)$ & value \\
\hline Verbal intelligence & Verbal IQ & $56.7(12.6)$ & $44.1(12.1)$ & $0.004 *$ \\
\hline Working memory & Verbal span & $5.1(0.87)$ & $4.5(1.1)$ & 0.059 \\
\hline \multirow[t]{4}{*}{ (slave systems) } & Visuospatial span & $4.4(0.7)$ & $3.9(0.9)$ & 0.091 \\
\hline & CVLT Learning (\%) & $62.8(12.9)$ & $23.6(9.1)$ & $<.001 *$ \\
\hline & CVLT Short-term Free recall (\%) & $57.3(24.5)$ & $5.2(8.9)$ & $<.001 *$ \\
\hline & CVLT Short-term Cued recall (\%) & $66.7(18.7)$ & $2.1(27.2)$ & $<.001 *$ \\
\hline \multirow[t]{4}{*}{ Declarative memory } & CVLT Long term Free recall (\%) & $61.4(19.7)$ & $4.9(11.1)$ & $<.001 *$ \\
\hline & CVLT Long term Cued recall (\%) & $67.4(19.1)$ & $3.2(22.5)$ & $<.001 *$ \\
\hline & CVLT Recognition (\%) & $81.3(13.3)$ & $17.1(34.9)$ & $<.001 *$ \\
\hline & Composite score & $0.57(0.46)$ & $-1.1(0.42)$ & $<.001 *$ \\
\hline
\end{tabular}

Differences between controls' and patients' means were evaluated by performing two-tailed $t$-tests. The Bonferroni correction for multiple comparisons was applied. * Significant difference between AD patients and controls. 
Table 3: Correlations between verbal intelligence, working memory, declarative memory and cognitive procedural learning

\begin{tabular}{|c|c|c|c|c|c|c|}
\hline \multirow{2}{*}{\multicolumn{3}{|c|}{ Predictive independent variables }} & \multirow{2}{*}{\multicolumn{2}{|c|}{$\begin{array}{l}\text { Session } 1 \\
\mathrm{r}_{\mathrm{BP}}\end{array}$}} & \multirow{3}{*}{$\begin{array}{l}\text { Session } 2 \\
r_{B P} \\
-0.57\end{array}$} & \multirow{3}{*}{$\begin{array}{l}\text { Session 3 } \\
r_{B P} \\
-0.57\end{array}$} \\
\hline & & & & & & \\
\hline Verbal intelligence & & Verbal IQ & -0.48 & -0.51 & & \\
\hline \multirow[t]{2}{*}{ Working memory } & Phonological loop & Verbal span & & -0.6 & & \\
\hline & Visuospatial sketchpad & Visuospatial span & & & & \\
\hline Declarative memory & & Composite score & -0.64 & & & \\
\hline
\end{tabular}

Only significant correlations are reported

AD patients' data are in bold and italics

$*: p<.05 ; * *: p<.01 ; * * *: p<.001$ 
Table 4: Best predictors of procedural learning in the AD and control groups

\begin{tabular}{|lllll|}
\hline \multirow{2}{*}{ Best predictors } & $\boldsymbol{\beta}$ coefficient & Differences in $\boldsymbol{\beta}$ \\
\cline { 3 - 5 } & & Controls & AD patients & $\begin{array}{l}\text { coefficients between } \\
\text { groups }\end{array}$ \\
\hline \multirow{2}{*}{ Session 1 } & Declarative memory & $0.64^{*}$ & 0.03 & $@$ \\
& Phonological loop & -0.48 & $-0.60^{*}$ & NS \\
\hline Session 2 & Verbal intelligence & -0.26 & $-0.57^{*}$ & NS \\
\hline Session 3 & Verbal intelligence & -0.05 & $-0.57^{*}$ & @ \\
\hline
\end{tabular}

NS: not significant

*: best predictor for the learning session within the group; $p<.05$

@: significant difference between $\mathrm{AD}$ patients and controls; $p<.05$ 
Figure 1: Performance trends in terms of the sum of completion times (A) and the sum of the number of moves (B) per session in the TH task for AD patients and control participants. 